\title{
LA HISTORIA DE LA MEDICINA EN LAS ENFERMEDADES EPIDÉMICAS: ENTRE LA REALIDAD Y LA IMAGINACIÓN
}

\section{The History of Medicine in Epidemic Diseases: Between Reality and Imagination}

\author{
Luis Vicente SÁNCHEZ FERNÁNDEZ ${ }^{\mathrm{a}, \mathrm{b}}$; Covadonga PIPA MUÑIZ \\ ${ }^{a}$ Historia de la Medicina. Universidad de Oviedo. ${ }^{b}$ Centro de Salud de Lugones. SESPA (España). \\ Correo electrónico: sanchezvicente@uniovi.es
}

Fecha de recepción: 31 de agosto de 2020

Fecha de aceptación: 7 de agosto de 2020

Fecha de publicación: 29 de enero de 2021

Resumen

En este trabajo planteamos un breve ensayo de las epidemias o pandemias que ocurrieron en el mundo occidental y de las cuales tenemos documentación fehaciente desde el siglo XIV hasta el momento presente. En la misma línea exponemos que estamos inmersos en la epidemia del siglo XXI como consecuencia directa de la bonanza económica que estamos atravesando. En nuestro caso el escenario lo aplicamos a España y a Asturias; reflejando el número de fallecidos. La lucha por la vida con las carencias alimenticias que arrostró la humanidad de manera constante hasta el siglo XVIII que anulan toda posibilidad de defensa innata frente al mal, la muerte súbita de la peste bubónica, las deformaciones de la viruela, etc. ocupan la parte dura, pero es la realidad de la senda humana. En un segundo plano exponemos una serie de películas o de novelas que guardan cierta relación con los brotes epidémicos. Esto es pura fantasía.

Creemos que ambas visiones se pueden complementar porque el temor, el odio al extranjero, la inseguridad ante lo incierto, el aislamiento, el reflejo de huída, el miedo a la muerte o la búsqueda de un remedio curativo son situaciones reales en ambos mundos.

Palabras clave: epidemias; peste; COVID-19; literatura; cine.

\section{Abstract}

In this work we presented a brief essay of the epidemics or pandemics that took place in the Western world and from which we have reliable documentation from the fourteenth century to the 


\title{
LA HISTORIA DE LA MEDICINA EN LAS ENFERMEDADES EPIDÉMICAS: \\ ENTRE LA REALIDAD Y LA IMAGINACIÓN \\ LUIS VICENTE SÁNCHEZ FERNÁNDEZ; COVADONGA PIPA MUÑIZ
}

\begin{abstract}
present moment. In the same vein we say that we are immersed in the epidemic of the $21^{\text {st }}$ century as a direct consequence of the economic bonanza we are going through. In our case the scenario is applied to Spain and Asturias; reflecting the number of deaths. The struggle for life with the food deficiencies that constantly engrified humanity until the eighteenth century that nullify any possibility of innate defense against evil, the sudden death of bubonic plague, the deformations of smalllpox, etc. occupy the hard part, but it is the reality of the human path. In the background we expose a series of films or novels correlated with outbreaks. This is pure fantasy.

We believe that both visions can be complemented because fear, hatred of the foreigner, insecurity about future, isolation, the reflection of flight, the fear of death or the search for a healing remedy are real situations in both worlds.
\end{abstract}

Keywords: epidemics; plague; COVID-19; literature; movie theater.

\section{INTRODUCCIÓN}

La enfermedad es inherente a la propia vida. Es más, los seres humanos estamos rodeados de millones de seres microscópicos, "enemigos invisibles", con los que compartimos hábitat. Residen sobre la tierra con una antigüedad de 4.000 millones de años. También destacamos como nuestro cuerpo está colonizado por millones de estos microorganismos de unas 400 especies diferentes que mayoritariamente nos benefician, ya que gracias a ellos obtenemos vitaminas y nutrientes. Veamos que patología más frecuente se produce según los tipos clasificatorios:

Bacterias: difteria o garrotillo (Corynebacterium diphtheriae), tos ferina (Bordetella pertussis), cólera (Vibrio cholerae), tuberculosis (Mycobacterium tuberculosis), lepra (Mycobacterium leprae), tétanos (Clostridium tetani) y peste (Yersinia pestis).

Parásitos: malaria (género Plasmodium).

Virus con RNA: fiebre amarilla (arbovirus del género Flavivirus), hepatitis (virus de la hepatitis: A, Cy E), fiebre del Nilo occidental (familia Flavivididiae), dengue (familia Flavivididiae), poliomielitis (poliovirus), gripe (familia Orthomyxoviridae), resfriado común (varias familias: Rhinovirus, Coronaviridae, Adenoviridae, etc.), rubeola (virus de la rubeola, familia Matonaviridae), sarampión (virus del sarampión, familia Paramyxoviridae), paperas (paramixovirus), rabia (virus de la rabia), sida (virus de inmunodeficiencia humana), diarrea (norovirus, rotavirus, etc.), ébola (ebolavirus) y COVID-19 (coronavirus) y con DNA: varicela (virus varicela zóster), papiloma (virus del papiloma humano), herpes (virus herpes simple o zóster), hepatitis B (familia Hepadnaviridiae) y viruela (Variola virus). Igualmente ambas variedades pueden ser causantes de algunos cánceres.

\section{Hongos.}

Nuestros antepasados, con unos dos millones de años de existencia, dejaron el nomadismo del Paleolítico hace unos 12.000 años; su modo de vida se basada en la caza, la recolección y el carroñeo. Aún residiendo en un "entorno natural" padecieron dolencias similares a las de los primates salvajes; su esperanza de vida se situaba alrededor de los 30 años. Grupo humano sustituido por otro sedenterio al transformarse en agricultores y ganaderos. Con esta Revolución Neolítica (12000-5000 a. C.) se modificó la estructura nosológica con la aparición de crisis de subsistencia consecuencia de las modificaciones clímáticas; en la misma línea, se añadieron otras por la convivivencia con animales salvajes que consiguieron domesticar. Con esta sinergia muchos microbios dieron el salto a las personas, caso de la triquinosis (Trichinella spiralis), 


\section{LA HISTORIA DE LA MEDICINA EN LAS ENFERMEDADES EPIDÉMICAS: \\ ENTRE LA REALIDAD Y LA IMAGINACIÓN \\ LUIS VICENTE SÁNCHEZ FERNÁNDEZ; COVADONGA PIPA MUÑIZ}

la tuberculosis (Mycobacterium tuberculosis) o la esquistosomiasis (Schistosoma mansoni). Es posible que también hayan padecido las primeras epidemias debidas al incremento del núcleo poblacional.

El dato documental más antiguo al respecto se encuentra en La Biblia, siglo XII a. C., de esta manera que en el Éxodo Jehová ordenó a Moisés que esparciese cenizas en dirección al Faraón para que surgieran sobre los egipcios "tumores postemados así en los hombres como en las bestias" o de como el mismo informó a su pueblo disoluto que "Yahvé hará que se te pegue la peste". También el libro de Los Salmos contiene muchas oraciones pidiendo protección a Dios ante estos desastres sanitarios.

Otros episodios pestíferos famosos del pasado pueden ser la "plaga de Atenas", 430 a. C. y detallada por Tucídides; es posible que fuese tifus exantemático. Durante las Guerras del Peloponeso, 431 a. C.-404 a. C., apareció un cuadro compatible con viruela. O de cómo en el 541 de nuestra era afloró en Egipto una dolencia conocida como "pandemia de Justiniano" extendida por Bizancio, se cree que fuese peste bubónica.

Con Hipócrates (c. 460 a. C.- c. 377 a. C.), y su Corpus Hippocraticum (especialmente con el Tratado de los aires, las aguas y los lugares y Epidemias), se sientan las bases del pensamiento racional por el que se admitía que el ambiente era la causa necesaria para el desarrollo de las enfermedades; desechando para siempre el aspecto divino.

Avanzando en el tiempo destacamos que ciertos padecimientos infecto-contagiosos fueron llevados al Nuevo Mundo por los europeos causando entre los aborígenes una gran mortalidad (las más temibles fueron la gripe, la viruela y el sarampión). El siguiente hito sobre el control de las epidemias le corresponde al inglés
Edward Jenner (1749-1823); en su tiempo era conocido que las lecheras estaban inmunizadas frente a la viruela y dedujo que la protcción se encontraba en el pus de las ampollas ubicadas en las ubres de las vacas. Con esta hipótesis raspó la piel de un niño de ocho años, James Phipps, el mencionado pus. Un tiempo después lo puso de nuevo ante contenido variólico sin que contrajera el mal. Con este ensayo descubrio la primera vacuna humana -vacuna viene de vaca- frente a la viruela; proceder, no exento de polémica, que se extendió por todo el mundo ${ }^{1}$. También resaltamos La Real Expedición Filantrópica de la Vacuna, 1803-1806, financiada por el rey Carlos IV (1748-1823), para llevar este proceder terapéutico hasta los confines del Imperio español. Tarea encomendada al cirujano Francisco Javier Balmis y ayudado por el médico Salvany ${ }^{2}$. La vacuna se mantuvo fresca gracias a que contaron con 22 niños huérfanos a quienes se la iban pasando de brazo a brazo ${ }^{a}$. La Organización Mundial de la Salud completó el empeño protector y se consiguió erradicar. A día de hoy es la única enfermedad infecto-contagiosa eliminada de la faz de la tierra.

\section{LAS EPIDEMIAS ACAECIDAS EN EL MUNDO OCCIDENTAL DESDE EL SIGLO XIV HASTA LA ACTUALIDAD Y SU LIGAZÓN CON LA LITERATURA Y EL CINE}

A continuación nos vamos a centrar, con hechos documentales, en las provocadas por virus o bacterias, desde el siglo XIV hasta la actualidad, incluyendo a Asturias. Veamos a continuación los embites de las plagas más importantes: peste negra, tifus exantemático, viruela, cólera, gripe, sida y coronavirus.

Peste negra o peste bubónica: Se trata de una zoonosis padecida por los roedores,

a. Las normas estipuladas para estos niños indicaban que "serán bien tratados, mantenidos y educados, hasta que tengan ocupación o destino con que vivir, conforme a su clase y devueltos a los pueblos de su naturaleza, los que se hubiesen sacado con esa condición". Tomado de Ramírez Martín, 2003: 85. 


\section{LA HISTORIA DE LA MEDICINA EN LAS ENFERMEDADES EPIDÉMICAS: \\ ENTRE LA REALIDAD Y LA IMAGINACIÓN \\ LUIS VICENTE SÁNCHEZ FERNÁNDEZ; COVADONGA PIPA MUÑIZ}

especialmente ratones (Rattus rattus) y que sólo de forma accidental afecta al hombre. Su origen fue Asia, proximidades del Himalaya, y su germen causal la bacteria Yersinia pestis que parasitó a la pulga Xenopsilla cheopis. Dolencia que a través de la "Ruta de la seda" invadió en 1346 Constantinola y diversos puertos del Mediterráneo para extenderse periódicamente por Europa hasta 1750. Este azote tiene la particularidad de ser la patología más espectacular por el trasfondo alcanzado en la memoria social debido a la alta mortalidad en la Edad Media. Desde mediados del siglo XIV hasta 1750 este mal acudió de forma periódica a Europa con una importante repercusión desde el punto de vista demográfico, puesto que se calcula una pérdida entre el 20 y el $50 \%$ de la población o dicho de otra manera la defunción de unos 25 millones de personas. Como no tenía cura los médicos de la época recomendaban: "pronta huida, larga ausencia, tarda vuelta". Llegó a España en 1347; luego siguieron diversas oleadas.

El deterioro más importante dentro del territorio astur, una de las provincias más pobre de la nación y con unos 150.000 habitantes, ocurrió durante el quinquenio 1598/1602 con la invasión de la llamada "Peste atántica", la máxima afectación recayó sobre los pobres y menesterosos del territorio rural con especial incidencia entre niños, adolescentes y mujeres.

Oviedo en aquel tiempo era una ciudad de pequeño tamaño, 1.930 habitantes, y sucia porque los vecinos arrojaban desde las ventanas las inmundicias a la vía pública. El personal se dedicaba al comercio, actividades artesanales o manufacturas para vender en el mercado franco. A la vez, poseían huertas y viñas con recolección de semillas, granos y frutos que daban a la urbe un tono de ruralidad. La mayoría de casas eran de madera con cocina y habitación común y no pocos compartían espacio con los animales domésticos. Cuestión ideal para que los ratones (Rattus rattus) que vivían en cuadras y tendejones se contaminaran con las pulgas infectadas y estallase un brote a mediados de agosto de 1598 , se mantuvo activa durante dieciocho meses y murieron unas 579 personas. Los profesionales asalariados por la corporación ovetense eran un médico y dos cirujanos barberos. Ante el aluvión de enfermos habilitaron el Hospital de Santa María Magdalena y la Malatería de San Lázaro; igualemente contrataron a dos enfermeras y a un farmacéutico.

En el municipio de Aller causó 246 difuntos y en la parroquia de San Martín de Valledor del concejo de Allande 142.

Novelas y cine en la peste bubónica

Diario del año de la peste. 1722. Autor: Daniel Defoe.

Se describe con gran exactitud y crudeza la epidemia de peste que asoló Londres y alrededores entre 1664 y 1666.

Decamerón. Principe Galeoto. 1352. Autor: Giovanni Boccacio.

Es un libro de cien cuentos o novelas cortas. Entre ellos hay una descripción de la peste bubónica que afecttó a Florencia en 1348.

Peste y cólera. 2012. Autor: Patrick Deville.

Analiza las enfermedades de la peste y del cólera. Centrándose específicamente en la figura del bacteriólogo franco-suizo Alexandre Yersin (1860-1943). Codescubridor, junto a Kitasato Shibasaburo, del bacilo responsable de la peste bubónica; bautizado así en su honor.

La peste. 1947. Autor: Albert Camus.

Novela que narra un brote de peste en la ciudad argelina de Orán. En 1992 el director Luis Puenzo la adaptó al cine manteniendo su nombre original ${ }^{3}$.

La peste negra. Pronto, lejos y tarde. 2006. Autor: Luis Miguel Guerra. 


\section{LA HISTORIA DE LA MEDICINA EN LAS ENFERMEDADES EPIDÉMICAS: \\ ENTRE LA REALIDAD Y LA IMAGINACIÓN \\ LUIS VICENTE SÁNCHEZ FERNÁNDEZ; COVADONGA PIPA MUÑIZ}

Siglo XIV, la peste bubónica asola a Europa. El papa Cllemte VI convoca un concilio de médicos para erradicar la pandemia. Los protagonistas son tres médicos (árabe, judío y cristiano) que buscan la manera de curarla.

Pánico en las calles. 1950. Director: Ellia Kazan ${ }^{4}$.

Refleja el empeño del médico Clint Reed, jefe del Sevicio de Salud Pública, y del capitán de policía Tom Warren para impedir la explosión de un brote de peste bubónica en Nueva Orleans (Luisiana).

Huye rápido, vete lejos. 2001. Autora: Fred Vargas.

Novela negra que plantea una epidemia de peste bubónica en el París actual, ciudad que se termina invadiendo por el miedo. En 2007 se adaptó al cine por el director Regis Wargnier con el mismo título. En España se estrenó como Plaga final.

Tifus exantemático ("tabardillo pintado"): Se trata de otro padecimiento medieval y es también originario del sudeste asiático; es producida por la bacteria Rickettsia prowazekii y se transmite por la pulga y el piojo del cuerpo humano, como portador de ambos insectos actúa una vez más la rata negra (Rattus rattus). Ocurre en brotes y se favorece por la sincronía hacinamiento, escasa higiene y hambre.

Desde el punto de vista histórico se acepta que la primera epidemia europea de tifus exantemático surgió en 1489 , fecha del asedio de las tropas castellanas a la Granada musulmana; se cree que llegó con los soldados chipriotas que tomaron parte en la contienda. En total mató a 17.000 milicianos cristianos. Con la Guerra de las Alpujarras (1568-1571) se extendió por toda la Península Ibérica. Una nueva crisis de subsistencia en el trienio 1605-1607 motivó una epidemia tan intensa que ese perido quedó designado como "año de los tabardillos". Padecimiento que asoló a los ejercitos de Napoleón por diferentes países de Europa y Rusia, que apareció en la Gran Guerra, en la Revolución bolchevique de 1917-1923, etc. Como ejemplo de la capacidad mortífera anotamos que durante el último episodio que citamos el deterioro socio-económico y la infección consecuente provocó la muerte de unos 25 millones de habitantes.

Otros brotes en España: 1903, 1906, 1910/15, $1919 / 20$ y en la posguerra española 1939/45 provocando la muerte al $15 \%$ de los infectados. Los últimos casos para nuestro país datan de 1960 .

Como caso particular destacamos que en 1573 hubo un brote de "tabardillu pintu" en Oviedo, hecho que se repitió varias veces durante el siglo XVIII. En 1786 afectó al concejo de Nava donde la población ingería únicamente "pan de maíz hecha su masa de una harina mohosa de algunos meses molida, sin levadura y sal". Provocó unos cien muertos. En 1790 apareció en Oviedo, en 1799 en Gijón, en 1802 en Corias (Cangas del Narcea), en 1875 en Villaviciosa y en Colunga, un año más tarde repitió en esta localidad y mató a 127 vecinos. En 1876 surgió en Piloña y en Cangas de Onís. En 1883 hizo acto de presencia en Las Regueras. En el quinquenio 1880-1884 mató a 929 asturianos. En 1938 invadió Siero.

\section{Novelas y cine en el tifus exantemático}

Tifus. 1943. Autor: Jean Paul Sartre.

Novela ambientada durante una epidemia de tifus ocurrida en Malasia. El autor, con un enfoque moral. aprovecha este padecimiento para hacer una crítica social. Relato en sintonía con La peste de Albert Camus.

El año del tifus. 2004. Autor: Edorta Jiménez Ormaetxea.

Narra las peripecias de unos marineros del siglo XVI enrolados en un buque de la Armada española rumbo a Inglaterra y su 


\section{LA HISTORIA DE LA MEDICINA EN LAS ENFERMEDADES EPIDÉMICAS: \\ ENTRE LA REALIDAD Y LA IMAGINACIÓN \\ LUIS VICENTE SÁNCHEZ FERNÁNDEZ; COVADONGA PIPA MUÑIZ}

modo de sobrellevar este mal. Igualmente expone como el aislamiento durante meses hace aflorar las miserias humanas.

1793. 2017. Autor: Niklas Natt och Dag Considerado el mejor libro 2017 en Suecia. La trama, una auténtica novela negra ambientada en Estocolmo durante el siglo XVIII, retrata el olor a podrido reinante con suciedad y ratas en las calles embarradas; simbolismo de una sociedad moralmente enfermiza y sin esperanza en el futuro.

Viruela: Enfermedad eruptiva, febril y contagiosa causada por el Pox-virus o virus de la viruela. Tiene una gran afinidad por la piel y se transmite principalmente por vía respiratoria, aunque el patógeno queda acantonado en las costras pudiendo contaminar a través de la ropas de los infectados. El único reservorio es el hombre. Existen indicios de que ya se padecía desde el Neolítico. Se consolidó en Europa a partir del siglo VI y alcanzó el rango de endémica hasta el XIX provocando una importante mortalidad, entre 200.000 y 600.000 europeros al año, especialmente en niños. La mayoría de ciegos era por su casusa. Fue llevada a América con el segundo viaje de Cristobal Colón. Tuvo una letalidad del 25 $\%$ (oscila entre el 20 y el $40 \%$ ). En la actualidad se encuentra erradicada gracias a la vacunación sistemática ideada por Edward Jenner (1749-1823).

La primera referencia de este mal en Asturias corresponde al médico Gaspar Casal (1680-1759), quien afirmaba que en 1720 se hallaba invadido todo el Principado. Desde esta fecha hasta 1951 tenemos documentos de afectación variolosa en casi todos los municipios de la provincia. En un breve resumen indicamos que en 1874 en el pueblo de Pedrosa la viruela causó el $44,44 \%$ del total de defunciones y en las caserías del ReboIlal-Berros el $57 \%$, ambos lugares ubicados en el concejo de Sariego. Entre 1880/84 hubo en territorio astur 1.273 defunciones con una letalidad del 37,76 \%; las deformaciones manifiestas (ceguera) alcanzaron al 7,91 \% de los afectados.

La técnica para la inmunización llegó a Asturias en 1801, concretamente en Gijón. En 1878 se organizó en Oviedo el primer "Centro de Vacunación" provincial a partir terneras inoculadas. El interés por la vacunación fue aumentando de tal manera que a finales del siglo XIX la mayoría de Ayuntamientos asturianos ofrecían este servicio a quien lo precisase; además, no se admitía en escuelas públicas y talleres a jóvenes sin la preceptiva inmunización.

\section{Novelas y cine en la viruela}

Ángeles custodios. Autora: 2010. Autora: Almudena de Arteaga.

Retrata la epopeya de la "Real Expedición Filantrápica de la Vacuna" diseñada por el rey Carlos IV para lleva esta técnica salvadora a los confines del Imperio español. Fue llevada al cine en 2016 por Javier Bardem como 22 ángeles.

Con idéntico propósito tenemos Para salvar el mundo, 2006. Autora: Julia Álvarez, Los héroes olvidados, 2011. Autor: Antonio Villanueva Edo. A flor de piel. 2015. Autor: Javier Moro. Los niños de la viruela. 2017. Autora: María Solar.

Películas películas donde destaca esta enfermedad son: Variola Vera. 1982 del director Goran Markovic; La puta del rey, 1991, de Axel Corti o Un asunto real, 2012, de Nicolaj Arcel. Vittorio Amadeo 5 .

Cólera morbo asiático: Se trata de la enfermadad más emblemática del siglo XIX en Europa. Padecimiento endémico de la India (Bengala y Delta del Ganges) expandida mundialmente por las tropas inglesas en forma de pandemias: 1821, 1834, 1855,1865 y 1885 . A su costa murieron unos 800.000 españoles. El gérmen causal, Bacillus vírgula, fue descubierto por el alemán Robert Koch 


\section{LA HISTORIA DE LA MEDICINA EN LAS ENFERMEDADES EPIDÉMICAS: \\ ENTRE LA REALIDAD Y LA IMAGINACIÓN \\ LUIS VICENTE SÁNCHEZ FERNÁNDEZ; COVADONGA PIPA MUÑIZ}

(1843-1910) en 1883. Transmisión oral-fecal, especialmente a través del agua contamida; esto es, enraiza con fuerza en aquellos lugares pobres donde existen malas condiciones de higiene.

Por su causa murieron unos 10 millones de europeos, cifra que representa entre el 1 y el $2 \%$ de la población.

Asturias padeció la primera epidemia en 1834 y fue preciso implantar un cordón sanitario sobre Noreña, concejo en el que murieron 477 personas. El brote de 1855 acarreó 3.319 difuntos, en 1865 provocó 78 óbitos y la última de 1885 dejó 83 muertes. Por tanto, esta pandemia mató a 3.957 asturianos.

\section{Novelas y cine en el cólera morbo asiático}

El médico fiel. 2008. Autor: Antonio Villanueva Edo.

Novela ambientada en Bilbao durante 1832. Describe dos estragos igual de horrorosos: el cólera y la primera Guerra carlista.

El húsar en el tejado. 1951. Autor: Jean Giono.

Libro ambientado en la Provenza francesa durante la epidemia de cólera de 1832. Película de igual nombre dirigida en 1995 por Jean Paul Rappeneau.

El velo pintado. 1925. Autor: William Somerset Maughan.

Novela ambientada durante una epidemia de cólera entre otros países en China. Se adaptó al cine en 1934, director: Richard Boleslawski y en 2006, director: John Curran.

Gripe de 1918/19: Patología endémica de Asia, a partir del siglo XIX se hizo global debido a los viajes sistemáticos a largas distancias. De naturaleza vírica, familia Ortomyxoviridae, género Influenza virus, tipo A, subtipo H1-N1, que cursa en brotes epidémicos durante los meses de invierno; de transmisión aérea por las gotitas de saliva.
Es posible que el primer brote gripal de la historia haya afectado al ejercito griego durante el sitio de Siracusa, 395 a. C. Igualmente se piensa que estuviese activa por todo el Occidente y Oriente Medio durante la Edad Media. Es factible que este mal traspasase el Océano Atlántico con los pasajeros del segundo viaje de Cristobal Colón, 1493.

Pandemia que posee el triste honor de ser conocida como "Gripe Española", porque nuestro país al ser neutral en la Primera Guerra Mundial notificó su presencia. El foco originario se ubica en Funston (Texas) detectado el 4 de marzo de 1918 en un campamento del ejército americano. Alcanzó España el 1 de abril y en julio ya estaba activa en Asturias. Cursó con tres brotes, el más dañido fue el de mediados de octubre de 1918 y la edad más afligida se encuentra entre 20 y 40 años. Provocó la muerte de cien millones de personas en todo el mundo equivalente al $1,1 \%$ de la población. A España le corresponden 270.000 defunciones; en Asturias tenemos 7.319 óbitos, de los cuales 640 corresponden a Oviedo, 307 a Gijón, 120 a Avilés y 700 a Cangas del Narcea.

En aquel tiempo la salud pública española era muy defectuosa por la insalubridad de las viviendas, las anomalías en infraestructuras relacionadas con el agua de bebida o el alcantarillado y con el hambre crónica que padecía el proletariado urbano, juntamente con la pobreza de la población.

Emergió en 1977, regresó de nuevo en 20092011 y sigue activa en la actualidad con una mortalidad muy baja.

Para no extendernos en demasía citaremos otras como la gripe "asiática" 1957-1958, Virus influenza A (H2N2) y la de "Hong Kong" 1968, Virus influenza $A$ (H3N2) que provocaron, cada una, entre uno y cuatro millones de muertes en el mundo; VIH/Sida en 1980, Virus de la inmunodeficiencia humana, desde que surgió hasta la actualidad se estima que hayan fallecido unos 32 


\section{LA HISTORIA DE LA MEDICINA EN LAS ENFERMEDADES EPIDÉMICAS: \\ ENTRE LA REALIDAD Y LA IMAGINACIÓN \\ LUIS VICENTE SÁNCHEZ FERNÁNDEZ; COVADONGA PIPA MUÑIZ}

millones de personas; el Ébola, 2014-2016, causado por un virus de la familia Filoviridiae, género Ebolavirus; el sarampión provocado por ptro de la familia Paramyxoviridae del género Morbillivirus, que antes de la vacuna de 1963 provocaba a nivel global la muerte de unos dos millones de personas al año; la poliomielitis, generada por un polivirus del género Enterovirus, enfermedad que dejó una apreciable mortalidad y muchas secuelas físicas, etc.

Novelas y cine en la gripe de 1918/19

El cuaderno gris. 1966. Autor: Josep Pla.

Novela escrita entre marzo de 1918 y noviembre de 1919. Ambientada entre la Gran Guera y la epidemia de Gripe de 1918/19.

La danza de la muerte. 1978. Autor: Stephen King.

Describe el virus de la supergripe que se expandió por EEUU de América con una tasa de mortalidad del $90 \%$. Reeditada en 1990 como Apocalipsis.

El jinete pálido. 1918: La epidemia que cambió el mundo. 2018. Autora: Laura Spinney.

Analiza la pandemia de gripe de 1918/19 destacando el que haya matado a su costa cien millones de personas en todo el mundo.

The Andromeda Strain, traducida como La amenaza de Andrómeda. 1966. Autor: Michael Crichton.

Novela de ciencia-ficción exponiendo como un grupo de científicos estadounidenses está preocupado por la posibilidad de que las sondas espaciales enviadas al espacio regresen a la tierra con contaminación extraterrestre. En 1971 se llevó al cine de la mano de Robert Wisez, en 2008 se recreó en televisión como miniserie.

Sida: Enfermedad provocada por el virus, retrovirus, de la inmunodeficiencia humana (VIH-1 y 2), comenzó a ser diagnosticado en EEUU de América en 1981. Se trata de una zoonosis, el reservorio sería un simio (chimpancé y gorila) ${ }^{b}$. Es posible que el paso de estos animales al hombre haya ocurrido al ponerse en contacto la sangre, caso de heridas, durante las cacerías o bien a través de la comida de carne de chimpances contaminados.

El epicentro tuvo su origen en 1920 en Kinsasa, capital de la República Democrática del Congo. A partir de 1960 se diseminó por todo el mundo dejando una estela de 33 millones de defunciones. En el África Subsahariana el $30 \%$ de la población es seropositivo.

A día de hoy sigue sin tener cura, pero la terapia específica está permitiendo que la infección se transforme en un enfemedad crónica y controlada 6 . Para concienciar de que esta epidemia sigue activa el 1 de diciembre se celebra el "Día Mundial del Sida". En 2017 mató a 442 personas en España, de las cuales 13 eran asturianas.

Novelas y cine en el sida

El desbarrancadero. 2001. Autor: Fernando Vallejo.

La trama plantea es la confesión de Darío, enfermo de SIDA, cuando se ve en el final de su vida.

Plus grands que l'amour. Traducido como Más grande que el amor. 1990. Autor: Dominique Lapierre.

Narra las vivencias de enfermos neoyorquinos de Sida apoyados por médicos e investigadores. Ambientada en los años 80 del siglo pasado cuando la enfermedad carecía de cualquier forma de terapia.

b. Detectado por primera vez por el equipo del Instituto Pasteur (París) bajo la dirreción Françoise Barré-Sinoussi, Jean-Claude Chermann y Luc Montagnier.

Rev. Med. Cine. 2020; 16 (e), 195-205 Ediciones Universidad de Salamanca / @®@ J. Med. Mov., 2020; 16 (e), 195-205 [ 202 ] 


\section{LA HISTORIA DE LA MEDICINA EN LAS ENFERMEDADES EPIDÉMICAS: \\ ENTRE LA REALIDAD Y LA IMAGINACIÓN \\ LUIS VICENTE SÁNCHEZ FERNÁNDEZ; COVADONGA PIPA MUÑIZ}

Before Night Falls. 1990, traducido como: Antes que anochezca. 1996. Autor: Reinaldo Arenas.

Relato autobiográfico de un homosexual en la Cuba de Fidel Castro que se exiliado en los EEUU de América. Cuenta su fase terminal del sida y opta por el suicidó el 7 de diciembre de 1990. Estremecedor testimonio personal y social. En el año 2000 se rodó una película con igual nombre dirigida por Julian Schnabel.

Moriré, pero mi memoria sobrevivirá. 2003. Autor: Henning Mankell.

Reflexión personal sobre el azote del sida en África, concretamente Uganda, plasmando el dolor por el sinnúmero de africanos fallecidos.

Al amigo que no me salvó la vida. 1990. Autor: Hervé Guinert.

Libro de gran impacto porque el propio autor confiesa que padece sida. La narración indica el deterioro personal y el anuncio de su próxima muerte. Es preciso tener en cuenta que en esa época la enfermedad no tenía tratamiento.

¿Por qué a mi? 1971. Autora: Valéria Piassa Polizzi.

Autobiográfica. Se considera una chica normal que contrajo el VIH/sida en su primera relacción sexual a la edad de 15 años.

Plaire, aimer et courir vite (Sorry Angel), traducida como Vivir Deprisa, Amar Despacio. 2018. Director: Christophe Honoré.

Cinta ambientada en París en los 90 del siglo pasado. Narra la relación entre un escritor de 40 años, que padece sida, y un estudiante de 22 años. Romance veraniego.

Philadelphia. 1993, de Jonathan Demme.

Primera película "de gran presupuesto" de Hollywood en plantear como un abogado homosexual contrae el sida por haber participado en una noche de sexo anónimo en un cine de la ciudad. Por este motivo es despedido de la empresa. El actor principal es Tom Hanks; ganó un Óscar por esta interpretación.

Angels in America. 2003, de Mike Nichols. En España: Ángeles en América.

Adaptada de la prestigiosa obra teatral de Tony Kushner, jugando con las vivencias de seis neoyorquinos dentro de una crisis de $\mathrm{VIH}, \mathrm{y}$ ambientada durante el gobierno del Presidente Reagan. Tiempo en el cual imperaba una importante homofobia.

And the Band Payy on, traducida como: En el filo de la duda, 1993, de Royer Spottiswoode.

Ubica el origen del virus del sida en África a mediados de los años setenta del siglo pasado hasta la muerte del actor Rock Hudson en1986. Planteamiento pionero que pretende demostrar la indiferencia de los gobiernos y de la sociedad porque se creía que era una enfermedad exclusiva de homosexuales y que posteriormente quedó acreditada como la "plaga del siglo XX".

COVID-19: El agente causal es una familia de virus descubierta en los años sesenta del siglo pasado de aspecto de corona, de ahí su nombre. Se desconoce su origen (probable entre animales salvajes), el contagio es a través de las gotas de saliva o por contacto con material infectado que luego entra por las mucosas. En los últimos años generó tres brotes epidémicos: SARS-CoV, síndrome respiratorio agudo y grave, iniciado en China en noviembre de 2002; MERS-CoV, síndrome respiratorio de Oriente Medio, detectado en 2012 en Arabia Saudí y el COVID-19 detectado en Wuhan (China) en diciembre de 2019 y que padecemos en el momento presente en calidad de pandemia decretada por la Organización Mundial de la Salud. 


\section{LA HISTORIA DE LA MEDICINA EN LAS ENFERMEDADES EPIDÉMICAS: \\ ENTRE LA REALIDAD Y LA IMAGINACIÓN \\ LUIS VICENTE SÁNCHEZ FERNÁNDEZ; COVADONGA PIPA MUÑIZ}

El microorganismo causal es el coronavirus SARS-CoV-2 que tiene una letalidad mímima del $1 \%$ y máxima del $4 \%$. Entre el 6 y el $14 \%$ de los infectados desarrolla un cuadro clínico, que precisa hospitalización, caracterizado por insuficiencia respiratoria, shock séptico, daño multiorgánico y muerte. En 1997 Donald S. Burke, epidemiólogo y experto en enfermedes infecciosas, dio una conferencia, publicada posteriormente, en la que afirmaba la posibilidad que determinados virus pudieran provocar una nueva pandemia. En concreto apuntaba que los coronavirus

... deberían considerarse como serias amenzas para la salud de los seres humanos. Se trata de virus con una elevada tasa de evolucionabilidad y una capacidad probada para causar epidemias en las poblaciones de animales ${ }^{7}$.

\section{Novelas y cine en el COVID-19}

Los ojos de la oscuridad. 1981. Autor. Dean R. Koontz.

Describe un virus letal, Wuhan 400, originado en China, concretamente en Wuhan, capital de la provincia de Hubei. Premonición de lo ocurrido con el coronavirus de 1019/20.

Otras películas inspiradas en padecimientos víricos son: Epidemia (Estallido en España). 1995. Se trata de un brote de fiebre hemorrágica. Director: Wolfgang Peterser; Contagio. 2011. Director: Steven Soderbergh y Virus. 2013. Director: Kim Sing-su.

\section{CONCLUSIONES}

Comparando las cifras de letalidad de las epidemias/pandemias del pasado apreciamos que la provocada por el coronavirus que estamos padeciendo se encuentra en cotas mucho más bajas, a pesar de las facilidades que le está aportando la globalización del comercio, los viajes, los cambios demográficos y un largo etcétera y esto es así gracias al sistema sanitario que tenemos. También resaltamos como en la antigüedad el consejo médico ya referido anteriormente indicaba una huida casi forzosa del lugar afectado. En el momento presente la única forma de lucha contra todos los males referidos es la que ofrece el propio cuerpo a través del sistema inmunitario ayudado por antibióticos, antivirales y vacunas. También es preciso aislar poblaciones infectadas quedándose "en casa", promover la higiene (lavado de manos), evitar grandes aglomeraciones, uso de la mascarilla, mantenimiento de una buena dieta y por supuesto seguir los consejos establecidos por los científicos. No descartamos que el impacto socio-económico repercuta de alguna manera en la salud de la población.

La última consideración es referente a la epidemia, también real, que estamos padeciendo en el siglo XXI por las enfermedades sociales no infecto-contagiosas y que no son otras que: alteraciones cardiovasculares, tumores malignos, accidentes cerebro-vasculares, obesidad mórbida, diabetes tipo 2, dislipemias y accidentes en sentido general. Afecciones perfectamente erradicables bajo el espíritu de Galeno de Pérgamo (129-c.201/216) y sus "ses res non naturales" (cosas no naturales) entendiendo como tal: aire y ambiente, comida y bebida, trabajo y descanso, sueño y vigilia, excreciones y secreciones, y los movimientos -cambios- del ánimo. Según este médico estas variables deberían de guiarse por el concepto aristotélico de "mesotes" o justo medio. Los consejos a aplicar a la sociedad del presente: no fumar, alcohol en la justa medida, no consumo de drogas, dieta adecuada (baja ingestión de grasas saturadas, azúcar y sal e incremento de frutas y verduras) $y$ algo de deporte. 


\section{LA HISTORIA DE LA MEDICINA EN LAS ENFERMEDADES EPIDÉMICAS: \\ ENTRE LA REALIDAD Y LA IMAGINACIÓN}

LUIS VICENTE SÁNCHEZ FERNÁNDEZ; COVADONGA PIPA MUÑIZ

\section{REFERENCIAS}

1. Riera Palmero J. La introducción de la Vacuna Jenneriana en España. An Real Acad Med Cir Vall. 2015; 52: 191-213.

2. Ramírez Martín SM. El niño y la vacura de la viruela rumbo a América: La Real Expedición Filantrópica de la V (1803-1806). Rev Complut Hist Am. 2003; 29: 77-101.

3. Ontoso Picón D. La Peste (1992). De Albert Camus a Luis Puenzo. Rev Med Cine 2006; 2(1): 3-9.
4. Caravias Martín F. La amenaza de las plagas: Pánico en las calles (1950). Rev Med Cine 2006; 2(3): 89-95.

5. García Sánchez JE, García Sánchez E. La viruela y el cine histórico. Rev Med Cine 2013; 9(3): 105-6.

6. Alcamí J. Introducción: Una breve historia del sida. Enferm Infecc Microbiol Clin. 2008;26 (Supl 11):1-4.

7. Quammen D. Contagio. La evolución de las pandemias. Barcelona: Editorial Debate, 2020.

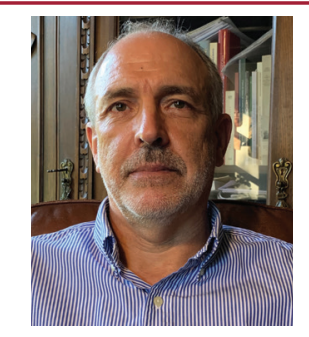

Luis Vicente Sánchez Fernández es Profesor asociado de Historia de la Ciencia ( $\mathrm{H}^{\mathrm{a}}$ de la Medicina) en la Facultad de Medicina de la Universidad de Oviedo. Médico del SESPA en el Servicio de Atención Continuada en el Centro de Salud de Lugones. Autor de cuatro libros y de varios artículos científicos de temas relacionados con la Historia de la medicina asturiana. 